\title{
El aprendizaje emocional con reforzadores secundarios no fortalece el recuerdo retroactivo de eventos relacionados
}

\author{
CAROLINA CuAdRADO-GÓmEZ \\ al262441@uji.es \\ ELISENDA BUEICHEKÚ \\ bueichek@uji.es \\ CÉSAR ÁVILA \\ avila@uji.es
}

\section{Resumen}

Introducción: Vivir experiencias con gran impacto emocional tiene un efecto trascendental sobre la memoria, así lo demuestran diversos estudios donde se defiende que los eventos emocionales se retienen mejor que los eventos neutros. Un tema de interés científico es el efecto de las nuevas experiencias emocionales sobre recuerdos relacionados previos. El presente estudio tuvo como objetivo investigar el efecto que tiene un evento emocional sobre el recuerdo retroactivo de eventos relacionados conceptualmente. Método: 25 estudiantes universitarios sanos completaron una tarea de codificación (compuesta por dos fases: pre-condicionamiento y condicionamiento) y una tarea de reconocimiento. El pre-condicionamiento consistía en clasificar categóricamente 90 imágenes de animales o herramientas. En el condicionamiento se presentaron 45 imágenes nuevas de cada categoría, una de las cuales fue asociada a un castigo monetario/social. Los participantes debían indicar si esperaban perder dinero en cada ensayo. Finalmente, $24 \mathrm{~h}$ después, se realizó la tarea de reconocimiento sorpresa. Resultados: Los resultados indicaron un mejor recuerdo a las 24 horas de la categoría castigada en el condicionamiento, sin embargo los ítems de esta categoría presentados en el pre-condicionamiento se recordaron peor. Conclusión: De manera novedosa, los resultados sugieren que el castigo mediante reforzador secundario causa un efecto inhibitorio de recuerdo en el pre-condicionamiento de la categoría castigada. Es decir, un evento emocional futuro puede afectar al recuerdo de eventos relacionados, que han sido codificados anteriormente, haciendo que estos se recuerden peor.

Palabras clave: emoción, aprendizaje, recuerdo, memoria retroactiva, condicionamiento 


\begin{abstract}
Introduction: Living experiences with great emotional impact has a transcendental effect on memory, as shown by several studies where it is argued that emotional events are retained better than neutral events than neutral events. A topic of scientific interest is the effect of new emotional experiences on previous related memories. The presented study aimed to investigate the effect of an emotional event on the retroactive memory of conceptually related events. Methodology: 25 healthy university students completed encoding task (composed of two phases: pre-conditioning and conditioning) and a recognition task. In the pre-conditioning, participants had to classify 90 images into animals and tools. Later, in the conditioning stage, 45 new images of each category were presented, one of which was associated with monetary / social punishment. Participants should indicate whether they expected to lose money or not in each trial. Finally, 24 hours later, the task of surprise recognition was performed. Results: The results replicated a better memory at 24 hours for the category punished in the conditioning, but the items of this category presented in the pre-conditioning, were worse remembered. Conclusion: Newly manner, the results suggest that punishment by a secondary reinforcement provokes an inhibitor effect of memory in the pre-conditioning of the punished category. That is, a future emotional event can affect the memory of related events, which have been previously codified, making them remember worse.
\end{abstract}

Key words: emotion, learning, memory, retroactive memory, conditioning

\title{
Introducción
}

A menudo los eventos emocionales se recuerdan con mayor exactitud y viveza que los eventos que carecen de un componente emocional (Buchanan, 2007). Este sesgo del recuerdo a favor de los estímulos emocionales, tiene una explicación evolutiva, ya que es un mecanismo de supervivencia (Dunsmoor, Martin y LaBar, 2012). Este mecanismo nos ha ayudado a acercarnos a lo apetitivo (como pueden ser fuentes de energía) y alejarnos de lo aversivo (depredadores), a dar respuestas óptimas ante un entorno cambiante. Es decir, la función biológica primaria de las emociones es la adaptación de la conducta a situaciones que resulten relevantes para el individuo (Aguado, 2002). Un tema de gran relevancia científica, en el cual se ha centrado este estudio, es conocer como los eventos emocionales afectan al recuerdo de otros eventos relacionados.

Las emociones son reacciones psicofisiológicas que nos permiten adaptarnos a los estímulos ambientales o de uno mismo. Involucran un conjunto de pensamientos, actitudes y creencias sobre el mundo que utilizamos para valorar una situación concreta y, por tanto, influyen en el modo en el que se percibe dicha situación. Sirven para establecer nuestra posición con respecto a nuestro entorno, y nos impulsan hacia ciertas personas, objetos, acciones, ideas y nos alejan de otros (Levenson, 1999). Las emociones tienen un papel fundamental en la memoria, puesto que son factores alertadores a través de los cuales la memoria se fija con mayor facilidad (Justel, Psyrdellis, y Ruetti, 2013; Loubon y Franco, 2010). De hecho, la estrecha relación existente entre las emociones y la memoria, está sustentada por numerosas investigaciones (Christianson y Loftus, 1987; Bradley, Greenwald, Petry, y Lang, 1992; LaBar, Gatenby, Gore, LeDoux, y Phelps, 1998; Quevedo et al., 2003; Bobes García, Bousoño Gar- 
cía, Calcedo Barba, y González García-Portilla, 2003; Buchanan, 2007; Knight y Mather, 2009; Justel, Psyrdellis, y Ruetti, 2013). En términos generales, es posible afirmar que los eventos emocionales se recuerdan mejor que los sucesos más triviales. De hecho, la memoria de sucesos asociados a diferentes emociones se adquiere con mayor facilidad y se mantiene a lo largo del tiempo (Christianson y Loftus, 1987).

A pesar de esta estrecha relación entre la emoción y la memoria, existen pocos estímulos de gran relevancia emocional. Es decir, la mayoría de los estímulos se procesan como eventos triviales, sin relevancia y, por tanto, se recuerdan poco. Ahora bien, puede ocurrir que un evento emocional presente facilite el recuerdo de los sucesos que inicialmente eran triviales (Dunsmoor, Murty, Davachi y Phelps, 2015). Desde la perspectiva de la memoria adaptativa es fundamental que los detalles aparentemente sin importancia puedan almacenarse en la memoria, al menos temporalmente, en caso de que esta información adquiera relevancia algún tiempo después. Dunsmoor y cols. (2015), intentaron demostrar como memorias inicialmente débiles pueden fortalecerse si esta información posteriormente adquiere significado. En su estudio proporcionan pruebas de un aumento de la memoria retroactiva en los seres humanos, que es selectiva a la información conceptual relacionada con un evento emocional futuro. Para ello, emplean dos tareas, una de codificación y otra de reconocimiento sorpresa a las $24 \mathrm{~h}$. La primera tarea constaba de tres fases, pre-condicionamiento, condicionamiento y post-condicionamiento. A lo largo de las tres fases se presentaban imágenes de dos categorías (animales y herramientas). Tanto en la primera fase (pre-condicionamiento) como en la última (post-condicionamiento), las imágenes no estaban vinculadas a ningún tipo de castigo. Sólo la fase de condicionamiento se asociaba una categoría (animal o herramienta) a una descarga (de forma contrabalanceada). A las $24 \mathrm{~h}$ se realizaba un reconocimiento sorpresa. Los resultados señalaron que no sólo se recordaban mejor los estímulos emocionales, es decir, los que habían sido asociados a la descarga, sino que este efecto se transladaba a nivel retroactivo. Es decir, se recuerdan también mejor los estímulos que pertenecen a la categoría castigada (EC+) del pre-condicionamiento a pesar de que estos no fueron asociados al castigo.

El impacto de un estímulo emocional sobre eventos codificados anteriormente ha sido poco estudiado. Por tanto, el objetivo del presente estudio es comprobar si el recuerdo de eventos, que no estaban vinculados con una emoción, pueden fortalecerse si en el futuro aparece un acontecimiento emocionalmente fuerte que se vincule conceptualmente con el primero (Dunsmoor, et al., 2015). Nuestra primera hipótesis es que habrá un mayor recuerdo de la categoría castigada (EC+) frente al recuerdo de la categoría no castigada (EC-) para los ítems del condicionamiento. La segunda hipótesis es que también habrá un mayor recuerdo de la categoría castigada (EC+) frente al recuerdo de la categoría no castigada (EC-) para los ítems del pre-condicionamiento.

\section{Método}

\section{Diseño}

Estudio experimental controlado y aleatorizado, con ocultación de la asignación a 8 versiones diferentes del experimento y enmascaramiento en el análisis de datos. El estudio estaba aprobado por el Comité Ético de la Universidad Jaume I. 


\section{Población y muestra}

Se seleccionaron 33 alumnos de la Universidad Jaume I. Los criterios de inclusión fueron: ser mayor de 18 años, firmar el consentimiento informado una vez entendida la finalidad del estudio y la metodología a emplear, no presentar enfermedad mental y no haber sido incluido anteriormente.La muestra final estaba compuesta por 25 participantes ( 9 hombres y 16 mujeres) con una edad de 21,92 $\pm 1,5$ años (media \pm desviación típica). Todos los participantes recibieron una remuneración económica tras finalizar el estudio.

\section{Materiales}

Imágenes

Las 8 versiones diferentes a las que fueron asignados los participantes del estudio, se elaboraron seleccionando un total de 360 imágenes: 180 imágenes de animales y 180 de herramientas, todas ellas a color sobre un fondo blanco (para evitar que el fondo pueda intervenir en el reconocimiento) y con una resolución de 800 × 600 píxeles. Los ítems estaban situados en el centro de la pantalla. Los estímulos fueron presentados mediante el software E-Prime 2.0, en un portátil Toshiba Satellite, con una pantalla de 15,6». Las imágenes se obtuvieron de recursos de libre acceso en internet. Durante el experimento ninguna imagen se presentaba más de una vez.

Los criterios para seleccionar las imágenes y contrabalancear las categorías fueron el número de sílabas y la frecuencia de uso de las palabras que denominan las imágenes. La selección se hizo mediante el programa EsPal (Duchon, Perea, Sebastián-Gallés, Martí \& Carreiras, 2013). Todas las imágenes se denominaban con una palabra simple (por ejemplo: gato o, martillo), no había palabras compuestas (por ejemplo: bicho palo o sierra mecánica).

\section{Tarea experimental}

El estudio estaba compuesto de dos sesiones experimentales (Figura 1). En la primera sesión se realizó una tarea denominada tarea de codificación, dónde se produjo el aprendizaje, y en la segunda sesión se realizó una tarea de reconocimiento, dónde se midió el recuerdo.

La tarea de codificación estaba compuesta por dos fases: pre-condicionamiento y condicionamiento. El pre-condicionamiento estaba formado por un total de 90 imágenes, 45 de animales y 45 de herramientas, que fueron presentadas durante 2,5 segundos con un intervalo inter-estimular de $6 \pm 2$ segundos en el que está incluida la pantalla en blanco con el punto de fijación, que aparece entre estímulos. La duración total del pre-condicionamiento fue de unos 8 minutos aproximadamente. En esta fase los participantes debían clasificar las imágenes en las dos categorías: animal o herramienta. Para ello, empleaba las teclas del teclado Z (animal) y $\mathrm{M}$ (herramienta). En esta fase, ninguna imagen fue asociada al castigo. A continuación, se llevó a cabo una asignación económica, en esta se presentaba en la pantalla del ordenador unas cifras que pasaban rápidamente y de forma aleatoria, estas cifras estaban en un rango de 20 a 140 euros, que es la cantidad que se les había indicado a los participantes que podían ganar en el experimento. Los participantes debían detener la presentación empleando la letra $\mathrm{H}$ del teclado, una vez detenida la presentación aparecía en pantalla la cifra que habían ganado. En todos los casos eran 90 euros. El dinero se les otorgaba en monedas de dos euros, ya que era una condición necesaria para desempeñar el castigo. 
El condicionamiento estaba formado por 90 imágenes, 45 de animales y 45 de herramientas. Todas ellas distintas a las del pre-condicionamiento. En esta parte, las imágenes se presentaban durante 4,2 segundos con un intervalo inter-estimular de $8 \pm 2$ segundos. Con una duración aproximada de 12 minutos. En esta fase los participantes debían indicar si esperaban perder dinero con la imagen que aparecía. Para ello, la tarea estaba diseñada de la siguiente forma: primero aparecía la imagen (de animal o herramienta), seguidamente la pregunta ¿Esperas perder dinero? Los participantes debían indicar sus respuestas empleando las teclas Z (sí) y M (no). Después podía aparecer, o no, una señal de castigo. La señal de castigo era una cara roja triste, que indicaba una pérdida monetaria de dos euros. Esta cantidad era retirada por el experimentador, dando lugar al castigo monetario/social. Se castigaban 30 imágenes de 45, dependiendo de la versión experimental se castigaba una categoría u otra. Estas estaban contrabalanceadas. En las versiones 1, 3, 5 y 7 se castigaba la categoría animales y en las versiones 2, 4, 6 y 8 se castigaba la categoría herramienta.

En la segunda sesión se realizaba un reconocimiento sorpresa. Se les explicaba a los participantes, que se les iba a presentar las imágenes visualizadas el día anterior, sin ningún tipo de modificación, junto a otras imágenes de animales y herramientas que no habían visto anteriormente. Los participantes debían indicar si la imagen la habían visto el día anterior o era nueva.

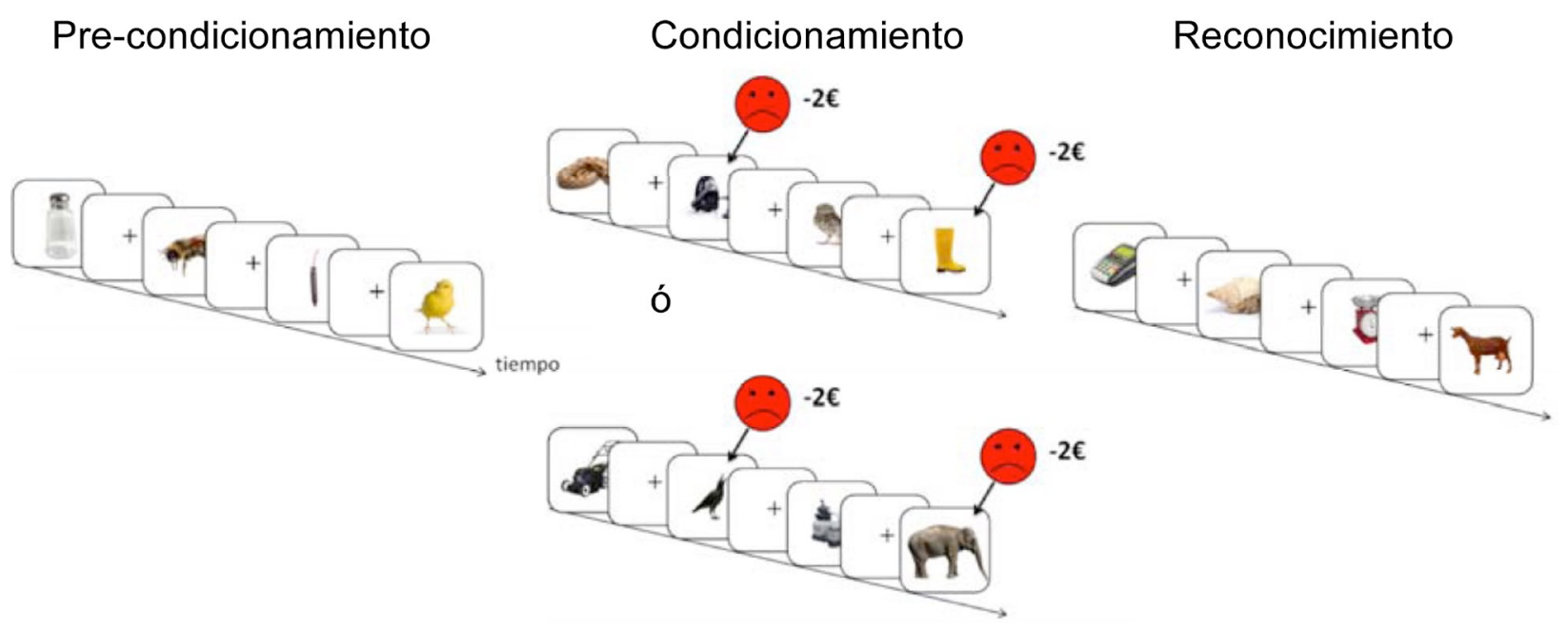

Figura 1. Tarea de codificación y tarea de reconocimiento

En la primera sesión realizaban una tarea de codificación. La tarea de codificación estaba compuesta por dos fases: pre-condicionamiento y condicionamiento. En el pre-condicionamiento ninguna imagen estaba asociada a un castigo. En la fase de condicionamiento una categoría era asociada a un castigo monetario/social. En la segunda sesión se realizaba un test de reconocimiento sorpresa a las 24 horas. 30 
Procedimiento

Antes de empezar la sesión experimental, los participantes debían firmar el consentimiento informado. Seguidamente, se procedía a iniciar la sesión experimental. En la primera sesión se realizaba la tarea de codificación. La sesión se iniciaba con la fase de pre-condicionamiento, dónde los participantes debían clasificar las imágenes en animales y herramientas. Una vez finalizada esta fase, se procedía a la asignación económica donde los sujetos recibían 90 euros. Se les explicaba que en la fase que de condicionamiento podían perder parte de este dinero y esto dependería de la señal de castigo. En el condicionamiento, 30 imágenes de una de las categorías estaban emparejadas con la señal de castigo. Por tanto, al finalizar el condicionamiento todos los participantes se quedaban con 30 euros, ya que cada vez que aparecía la señal de castigo se retiraban dos euros de los 90 euros asignados inicialmente. La segunda sesión se llevaba a cabo a las 24 horas, era una tarea de reconocimiento sorpresa. En esta sesión aparecían las imágenes de la tarea de codificación junto con las imágenes nuevas, también de las categorías de animales y herramientas, los participantes debían indicar si las imágenes presentadas eran nuevas o no.

\section{Análisis estadístico}

El análisis estadístico de los datos se realizó mediante un ANOVA 2x2 de medidas repetidas. El primer factor fue Fase (Pre-condicionamiento vs. Condicionamiento) y el segundo factor fue Categoría (Categoría castigada vs. Categoría no castigada). Calculamos los estadísticos descriptivos, la media y la desviación típica, para comparar el aprendizaje entre categorías en el pre-condicionamiento y en el condicionamiento. Para medir el tamaño del efecto empleamos la eta parcial al cuadrado $(\eta 2 p)$.

\section{Resultados}

La muestra final estaba compuesta por 25 participantes ( 9 hombres y 16 mujeres) con una edad de 21,92 $\pm 1,5$ años (media \pm desviación típica). Los resultados del ANOVA $2 \times 2$ señalan una interacción significativa entre los factores Fase $x$ Categoría $[F(1,24)=8,24, p=0,008$, $\eta 2 p=0,25]$, aunque los efectos principales de cada uno no alcazaran la significación mínima $(p>0.05)$. Esta interacción indica que se recuerdan más ítems de la categoría castigada en el condicionamiento $(\bar{x}=0,441 ; \sigma=0,128)$ en comparación con la categoría no castigada $(\bar{x}=0,41$; $\sigma=0,127)$. Sin embargo, este efecto se revierte en la fase de pre-condicionamiento, donde la categoría castigada se recuerda peor $(\bar{x}=0,4202 ; \sigma=0,136)$ que la categoría no castigada $(\bar{x}=0,469 ; \sigma=0,121)$ ( ver Figura 2). 


\section{Reconocimiento tras $24 \mathrm{~h}$}

\section{$\square$ Categoria castigada $\square$ Categoria NO castigada}

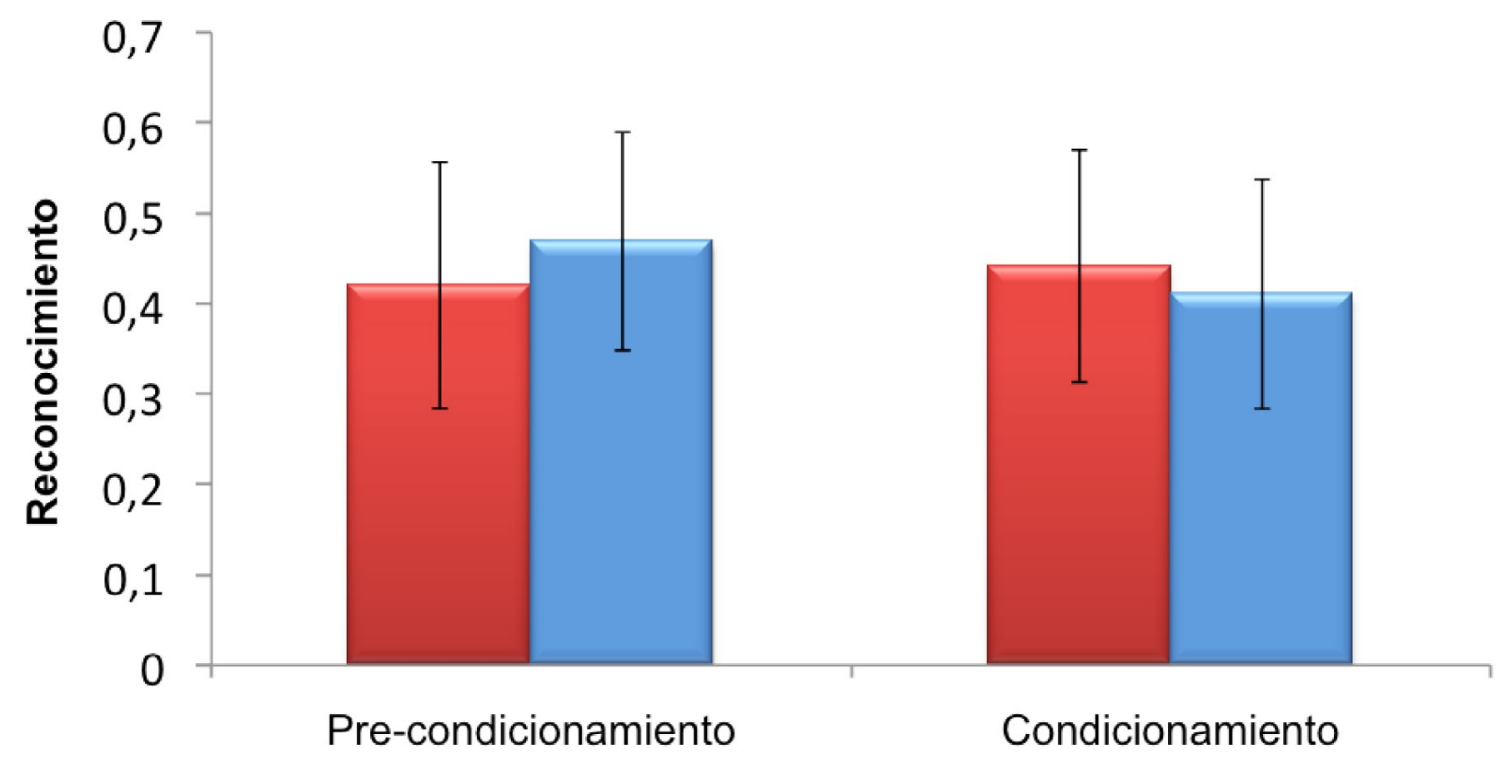

Figura 2. Reconocimiento tras las 24 horas

\section{Discusión y conclusión}

El objetivo del presente estudio fue investigar el efecto que tiene un evento emocional, elicitado con un reforzador secundario: monetario/social, sobre el recuerdo retroactivo de eventos relacionados conceptualmente. Para ello, el estudio estaba compuesto por una tarea de codificación y una tarea de reconocimiento sorpresa a las 24 horas. Los resultados de la tarea de reconocimiento indicaron que se recordaba mejor la categoría castigada en el condicionamiento y peor en el pre-condicionamiento. La novedad de este estudio es aportar evidencias sobre el impacto que tiene un evento emocional, a partir de un castigo monetario/social, sobre el recuerdo de eventos anteriores relacionados conceptualmente.

Numerosa literatura sustenta que los eventos emocionales se retienen mejor que los eventos neutros (Christianson y Loftus, 1987), y nuestros resultados también aportan datos a favor de esta afirmación. Sin embargo, no ha sido tan estudiado el efecto que tiene un evento emocional sobre eventos que han sido codificados anteriormente, y que guarden relación conceptual con el estímulo emocional. Dunsmoor y cols. (2015) demostraron que un evento emocional elicitado con un reforzador primario (una descarga eléctrica) produce una mejora en el recuerdo a nivel retroactivo de eventos relacionado. No obstante, a diferencia de estos autores nosotros no encontramos el mismo efecto en el pre-condicionamiento.

A partir de nuestros resultados podemos confirmar nuestra primera hipótesis, ya que se produce un mayor recuerdo de la categoría castigada $(E C+)$ frente al recuerdo de la categoría no castigada (EC-) para los ítems del condicionamiento. Por otra parte, debemos rechazar la segunda hipótesis, ya que no se produce una mejora a nivel retroactivo para los ítems del pre-condicionamiento que pertenecen a la categoría castigada. Por tanto, no encontramos el mismo efecto a nivel retroactivo que Dunsmoor y cols. (2015). Nuestros resultados sugieren 
que el castigo tiene un efecto inhibitorio en el reconocimiento de la categoría castigada, haciendo que los ítems que corresponden a la categoría castigada del pre-condicionamiento se recuerden menos.

Posiblemente estas diferencias se puedan atribuir a la emoción generada. En el estudio planteado por Dunsmoor y cols. (2015), emplean como estímulo incondicionado (EI) aversivo un reforzador primario, una descarga. Sin embargo, en nuestro estudio hemos empleado un reforzador secundario, concretamente un castigo monetario/social. Los resultados de un estudio realizado por Delgado, Labouliere y Phelps (2006) demostraron cómo un reforzador secundario, como el dinero, podía ser un estímulo incondicionado efectivo para un paradigma de condicionamiento aversivo. Sin embargo, no era tan efectivo como un reforzador primario. No obstante, Delgado y cols. (2006) no comparaban el efecto de los reforzadores en la consolidación de ítems previos. Ahora bien, para poder explicar que las diferencias de los resultados son atribuibles al tipo de reforzador, es necesaria más literatura al respecto. A partir de los resultados que disponemos, podemos interpretar que un reforzador secundario (monetario/ social) no presenta la fuerza necesaria para producir la mejora a nivel retroactivo.

Otra diferencia importante es que estamos realizando una comparación entre dos estudios con una diferencia muestral considerable, ya que el estudio de Dunsmoor y cols. (2015) dispone de una muestra de 119 sujetos frente a los 25 participantes que componen nuestro estudio. Futuros estudios podrían dirigirse a salvar estas diferencias y, además, incorporar el uso de reforzadores primarios con el objetivo de registrar el valor aversivo el castigo

En conclusión, debido a la escasez de estudios que integren emoción, aprendizaje y memoria a nivel de categorías conceptuales y que evalúen su efecto a nivel retroactivo, la aportación que podemos hacer a partir de los resultados de nuestro estudio es que un reforzador secundario no produce una mejora en el recuerdo anterior para categorías relacionadas conceptualmente.

\section{Referencias bibliográficas}

Aguado, L. (2002). Procesos cognitivos y sistemas cerebrales de la emoción. Revista de Neurología, 34(12), 1161-1170.

Bobes García, J., Bousoño García, M., Calcedo Barba, A. y González García-Portilla, M. P. (2003). Trastorno de Estrés Postraumático. Barcelona: Masson.

Bradley, M. M., Greenwald, M. K., Petry, M. C., y Lang, P. J. (1992). Remembering Pictures: Pleasure and Arousal in Memory. Journal of Experimental Psychology: Learning, Memory and Cognition, 2, 379-390.

Buchanan, T. W. (2007). Retrieval of Emotional Memories. Psychological Bulletin, 133(5), 761779. doi: 10.1037/0033-2909.133.5.761.

Christianson, S., y Loftus, E. (1987). Memory for Traumatic Events. Applied Cognitive Psychology, 1, 225-239.

Delgado, M. R., Labouliere, C. D., y Phelps, E. A. (2006). Fear of losing Money? Aversive conditioning with secondary reinforcers. SCAN, 1, 250-259. doi:10.1093/scan/nsI025.

Duchon, A., Perea, M., Sebastián-Gallés, Martí, A. y Carreiras, M. (2013). EsPal: One-stop shopping for Spanish Word properties. Behavior Research Methods, 45, 1246-1258. doi. 10.3758/s13428-013-0326-1

Dunsmoor, J. E., Martin, A., y LaBar, K. S. (2012). Role of conceptual knowledge in learning and retention of conditioned fear. Biological Psychology, 89(2), 300-305. doi: 10.1016/j. biopsycho.2011.11.002. 
Dunsmoor, J. E., Murty, V. P., Davachi, L., y Phelps, E. A. (2015). Emotional learning selectively and retroactively strengthens memories for related events. Nature, 520 (7547), 345-348. doi: 10.1038/nature14106.

Justel, N., Psyrdellis, M., y Ruetti, E. (2013). Modulación de la memoria emocional: Una revisión de los principales factores que afectan los recuerdos. Suma Psicológica, 20, 163174. doi: 10.14349/sumapsi2013.1276.

Knight, M., y Mather, M. (2009). Reconciling findings of emotion-induced memory enhancement and impairment of preceding ítems. Emotion, 9(6), 763-781. doi:10.1037/ a0017281.

LaBar, K. S., Gatenby, C., Gore, J. C., LeDoux, J. E., y Phelps, E. A. (1988). Human Amygdala Activation during Conditioned Fear Acquisition and Extintion: a Mixed- Trial fMRI Study. Cell Press, 20, 937-945.

Levenson, R. W. (1999). The Intrapersonal Functions of Emotion. Cognition and Emotion, 13(5), 481-504.

Loubon, C. O., y Franco, J. C. (2010). Neurofisiología del aprendizaje y la memoria. Plasticidad neuronal. IMedPub Journals, 6(1), 2. doi: 10.3823/048.

Quevedo, J., Sant' Anna, M. K., Madruga, M., Lovato, I., De-Paris, F., Kapczinski, F., Izquierdo, I., y Cahill, L. (2003). Differential effects of emotional arousal in short- and long-term memory in healthy adults. Neurobiology of Learning and Memory, 79, 132-135.

Ruetti, E., Mustaca, A., y Bentosela, M. (2008). Memoria emocional: Efectos de la corticosterona sobre los recuerdos. Revista Latinoamericana de Psicología, 40 (3), 461-474. 